\title{
Aldehydes-Aided Lignin-First Deconstruction Strategy for Facilitating Lignin Monomers and Fermentable Glucose Production from Poplar Wood
}

\author{
Tian-Ying Chen ${ }^{1}$, Cheng-Ye Ma ${ }^{1,2}$, Dou-Yong Min ${ }^{3}$, Chuan-Fu Liu ${ }^{4}{ }^{\mathbb{D}}$, Shao-Ni Sun ${ }^{1}$, \\ Xue-Fei Cao ${ }^{1}$, Jia-Long Wen ${ }^{1,2, * \mathbb{C}}$, Tong-Qi Yuan ${ }^{1,2}$ and Run-Cang Sun ${ }^{1}$ \\ 1 Beijing Key Laboratory of Lignocellulosic Chemistry, Beijing Forestry University, Beijing 100083, China; \\ tianyingchen15@163.com (T.-Y.C.); chengye.ma@foxmail.com (C.-Y.M.); sunshaoni@126.com (S.-N.S.); \\ caoxuefei@bjfu.edu.cn (X.-F.C.); tq581234@bjfu.edu.cn (T.-Q.Y.); rcsun3@bjfu.edu.cn (R.-C.S.) \\ 2 Beijing Advanced Innovation Center for Tree Breeding by Molecular Design, Beijing Forestry University, \\ Beijing 100083, China \\ 3 Guangxi Key Laboratory of Clean Pulp \& Papermaking and Pollution Control, Nanning 530004, China; \\ mindouyong@gxu.edu.cn \\ 4 State Key Laboratory of Pulp and Paper Engineering, South China University of Technology, \\ Guangzhou 510640, China; chfliu@scut.edu.cn \\ * Correspondence: wenjialonghello@126.com or wenjialong@bjfu.edu.cn; Tel./Fax: +86-10-6233-6903
}

Received: 7 February 2020; Accepted: 27 February 2020; Published: 2 March 2020

\begin{abstract}
In this study, lignin with fine structures and facile enzymatic saccharifying residue were successively dissociated based on the lignin-first biomass deconstruction strategy. In the lignin-first process, aldehyde-protected lignin fractions were firstly isolated by acid-catalyzed dioxane extraction in the presence of formaldehyde (FA) and acetaldehyde (AA) and then analyzed by advanced nuclear magnetic resonance (NMR) spectroscopy and gel permeation chromatography (GPC). The optimized hydrogenolysis of the extracted lignin $\left(\mathrm{L}_{\mathrm{FA}}\right.$ and $\left.\mathrm{L}_{\mathrm{AA}}\right)$ resulted in a high yield $(42.57 \%$ and $33.00 \%)$ of lignin monomers with high product selectivity (mainly 2,6-dimethoxy-4-propylphenol) (39.93\% and $46.61 \%$ ). Moreover, the cellulose-rich residues were saccharified into fermentable glucose for bioethanol production. The glucose yield of the substrate $\left(\mathrm{R}_{\mathrm{AA}}\right)$ reached to $75.12 \%$, which was significantly higher than that $(15.4 \%)$ of the substrate $\left(\mathrm{R}_{\mathrm{FA}}\right)$. In short, the lignin-first biomass deconstruction by adding AA is a promising and sustainable process for producing value-added products (energy and fine chemicals) from lignocellulosic biomass.
\end{abstract}

Keywords: biomass; lignin; biomass deconstruction; NMR characterization; structural changes

\section{Introduction}

The value-added application of lignocellulosic biomass has become a research hotspot in response to all kinds of drivers, such as environmental friendliness [1], sustainable biofuel production [2], and bio-based chemicals [3]. Until now, the main objective of traditional lignocellulosic biorefinery was to obtain valuable products from the carbohydrate fractions (cellulose and hemicelluloses) [4], which have been extensively applied in various fields, including chemicals [5], fuels (bioethanol) [6,7], and materials [2]. Lignin, the most abundant aromatic polymer on earth, is the main component of biomass. However, the complex structure of lignin is a major impediment to the valorization of lignocellulose in various processes [8]. Due to the complex structures of lignin polymers from different industrial processes, the characterization of lignin fractions is highly needed prior to developing value-added chemicals and materials [9]. For example, hydroxycinnamic acid ( $p$-coumaric acid and ferulic acid) 
substructures in gramineous lignin can be easily transformed into vinyl phenolics (4-vinylphenol and 4-vinylguaiacol) though fast pyrolysis [10-13].

In general, lignin is comprised of three phenylpropanoid structural units, namely p-hydroxyphenyl $(\mathrm{H})$, guaiacyl $(\mathrm{G})$, and sinapyl $(\mathrm{S})$ units, which form aryl ether $(\mathrm{C}-\mathrm{O})$ bonds and carbon-carbon $(\mathrm{C}-\mathrm{C})$ bonds by free radical coupling reactions [14]. Among these, $\beta-O-4$ ether linkages are the richest in native lignin from different feedstocks [15]. In addition, lignin-derived monomers obtained from lignin macromolecules with specific structures can be further converted into renewable energy and aromatic chemicals [16]. However, it remains a challenge to obtain both high yields of lignin monomers and fermentable glucose from lignocellulosic biomass. Although many researches are focused on lignin depolymerization, they still fail to transform the isolated lignin polymers into lignin monomes in large-scale [17]. In fact, the low yields of monomers from lignin after the hydrogenolysis process not only depend on the hydrogenolysis methods (catalytic system and conditions), but also rely on the chemical structures of the starting lignin [17].

Recently, preventing the formation of reactive intermediates during the pretreatment process has been a general trend to obtain lignin with a high preservation of $\beta-O-4$ linkages for promoting lignin monomer production with high yields [18]. Nevertheless, high-preserved $\beta$-O-4 linkages do not always guarantee the generation of a high yield of monomers, because some moieties with $\beta-\mathrm{O}-4$ bonds are also linked to other moieties through carbon-carbon $(C-C)$ bonds [19]. The $C-C$ bonds, presented in native lignin or formed during lignin extraction, play an important role in the releasing of monomers. If native lignin in wood is directly degraded, new $\mathrm{C}-\mathrm{C}$ linkage generated by the isolation of lignin would be suppressed, and about $45 \%-50 \%$ of monomers could be obtained [20]. Meanwhile, the carbohydrate fractions of biomass would be affected by catalysts during native lignin degradation. Therefore, removing lignin at the beginning of the biorefinery process is not only a usually applied strategy to facilitate carbohydrate valorization, but also an integrated process for the utilization of fermentable glucose and lignin simultaneously [21]. However, the new C-C bonds would emerge during the process of separating these components, which has an inhibiting effect on depolymerizing under hydrogenolysis conditions due to the higher bond dissociation energies [22-24]. Compared with the traditional biorefinery process, the recent lignin-first biomass fractionation processes seem to be more promising and charming $[4,25]$, which not only prohibit lignin condensation, but also do not compromise the structural integrity of the carbohydrates, thereby implementing the active stabilization of strategies [4]. For example, Shuai et al. proposed a novel biomass fractionation strategy that fits well in the lignin-first strategy [25]. Essentially, it aims to stabilize reactive benzylic cations with formaldehyde by forming a 1,3-dioxane structure with the $\alpha$ - and $\gamma$-hydroxyl groups on lignin side chains to preserve these indispensable ether linkages during lignin extraction [25]. Subsequently, a recent study focusing on stabilizing the $\alpha, \gamma$-diol of lignin with acetaldehyde and propionaldehyde verified that the product selectivity of lignin monomers could significantly increase [26]. Indeed, the protection of $\beta-O-4$ linkages during lignin isolation processes can simultaneously minimize the condensation of lignin, which is beneficial to the production of lignin monomers with high yields [25-27]. However, considering the integrated biorefinery process for lignin monomers and glucose, the optimal condition for the process should be balanced along with environmental sustainability, operability, and target production. Therefore, the "lignin-first" strategy was designed to achieve the lignin valorization on the forefront of the biorefinery, followed by the utilization of carbohydrates.

Based on the above-mentioned investigations, this study mainly focuses on producing a high yield of lignin monomers and glucose, which are the basic building blocks for energy and chemicals under the current biorefinery scenario. In this study, the stabilized lignin samples are isolated from poplar wood (40-60 meshed and ball-milled poplar wood) based on different stabilization strategies (formaldehyde and acetaldehyde). The structural characteristics and the catalytic hydrogenolysis of lignin polymers obtained after different stabilization strategies as well as the enzymatic saccharification of the cellulose-rich residues are performed to evaluate the effects of different stabilization strategies on the production of high-value products. It is believed that the 
process based on the aldehydes-aided lignin-first deconstruction strategy can facilitate the production of fuels and chemicals from the lignocelluloses.

\section{Materials and Methods}

\subsection{Materials}

Poplar wood (triploid of Populus tomentosa Carr., 5 years old) was collected from Guanxian County (Shandong, China) in March, 2015, and the chemical compositions of the poplar wood were listed as follows: cellulose (45.82\%, mainly glucan), hemicelluloses $(21.06 \%$, including $0.50 \%$ rhamnan, $0.28 \%$ arabinan, $0.72 \%$ galactan, $16.7 \%$ xylan, $1.99 \%$ mannan, and $0.87 \%$ uronic acid), and lignin (22.78\%, $21.80 \%$ Klason lignin, and $0.98 \%$ acid-soluble lignin), as previously [28]. Before cutting into tiny pieces and grinding to pass a 40-60 mesh sieve, it was necessary to remove the bark and dry the trunk. All the extractives were extracted with benzene/ethanol (2:1, v/v) for $6 \mathrm{~h}$. The dewaxed samples were air-dried at $60{ }^{\circ} \mathrm{C}$ for $16 \mathrm{~h}$ and stored at $5{ }^{\circ} \mathrm{C}$ before use. A part of the dewaxed poplar wood (about $20 \mathrm{~g}$ ) was ball-milled with a planetary ball mill (Fritsch GmbH, P6, Germany) according to the description in a previous publication [29]. Information about used chemicals and solvents are presented in the supplementary material.

\subsection{Lignin-first Deconstruction of Poplar Wood}

In a $100 \mathrm{~mL}$ glass round-bottom flask, 40-60 meshed/ball-milled poplar samples $(5 \mathrm{~g})$ were mixed with $45 \mathrm{~mL}$ of 1,4-dioxane, $2.1 \mathrm{~mL}$ of $\mathrm{HCl}$ solution (37\%), and $5 \mathrm{~mL}$ of formaldehyde (FA, 37.0\%) or acetaldehyde (AA, $\geq 40.0 \%$ ) solution. In the control experiment, $3.45 \mathrm{~mL}$ of water was added instead of FA and AA. The process was performed in water baths at the setting conditions $\left(80^{\circ} \mathrm{C}, 450 \mathrm{rpm}\right)$, maintained for the targeted reaction time of $5 \mathrm{~h}$. After the set reaction, the mixture was centrifuged and washed to separate the different residues $\left(\mathrm{R}_{\mathrm{FA}}, \mathrm{R}_{\mathrm{AA}}, \mathrm{R}_{\text {Control }}, \mathrm{R}_{\mathrm{BM}-\mathrm{FA}}, \mathrm{L}_{\mathrm{BM}-\mathrm{AA}}\right.$, and $\left.\mathrm{R}_{\mathrm{BM}-\mathrm{Control}}\right)$ and filtrates. The concentrated filtrate (rotary evaporators, $50^{\circ} \mathrm{C}$ ) was slowly dropped into 10 volumes of $\mathrm{pH}=2.0$ acidic water to precipitate lignin under stirring at $600 \mathrm{rpm}$, then the obtained lignin was centrifuged, freeze-dried, and labeled as $\mathrm{L}_{40-60}\left(\mathrm{~L}_{\mathrm{Control}}, \mathrm{L}_{\mathrm{FA}}\right.$, and $\left.\mathrm{L}_{\mathrm{AA}}\right)$ and $\mathrm{L}_{\mathrm{BM}}\left(\mathrm{L}_{\mathrm{BM}-\mathrm{Control}}, \mathrm{L}_{\mathrm{BM}}-\mathrm{FA}\right.$, and $\left.\mathrm{L}_{\mathrm{BM}-\mathrm{AA}}\right)$, respectively.

\subsection{The production of Lignin Monomers via Hydrogenolysis}

All the lignin monomers were obtained by the hydrogenolysis of the extracted lignin in a $100 \mathrm{~mL}$ of high-pressure reactor (Beijing Century Sen-Long Instruments Company, Beijing, China). Meanwhile, the usage of organic solvents can prevent char formation [30]. To optimize the solvent system, FA-stabilized lignin $\left(\mathrm{L}_{\mathrm{FA}}\right)$ was selected to hydrogenolysis under frequently used solvents (THF/MeOH/dioxane). Typically, $200 \mathrm{mg} \mathrm{L}_{\mathrm{FA}}$ was added into the reactor along with $40 \mathrm{~mL}$ THF/MeOH/dioxane as the solvent and $20 \mathrm{mg} 5 \mathrm{wt} \% \mathrm{Ru} / \mathrm{C}$ as the catalyst, and filled with $4 \mathrm{MPa}$ of $\mathrm{H}_{2}$. The reactor was heated to the setting temperature $\left(250^{\circ} \mathrm{C}\right)$ under stirring at $500 \mathrm{rpm}$, and the reaction was held at this condition for 8 h. After the hydrogenolysis, the reactor was quenched by opening the built-in cooling coils inside the reactor. The catalyst could be completely isolated by filtration, and the filtrate as degradation products was filtrated with an organic strainer to be analyzed by gas chromatography- mass spectrometry (GC-MS), except for the resulting liquid obtained by dioxane. The solvent (dioxane) was removed by rotary evaporation at $50{ }^{\circ} \mathrm{C}$ and replaced by $40 \mathrm{~mL}$ THF prior to being analyzed by the GC-MS technique. To optimize the starting lignin feedstock, the hydrogenolysis degradation was performed on $\mathrm{L}_{\mathrm{AA}}$ and $\mathrm{L}_{\text {Control }}$. Typically, $200 \mathrm{mg}$ of lignin was mixed with $40 \mathrm{~mL}$ of THF and $20 \mathrm{mg}$ of $5 \mathrm{wt} \%$ $\mathrm{Ru} / \mathrm{C}$, and the experiment condition was the same as mentioned above.

\subsection{Enzymatic Hydrolysis of the Cellulose-rich Residues}

To evaluate the performance of the lignin-first extraction process on the digestibility of the remaining substrates (i.e., carbohydrates), the cellulose-rich residues of 40-60 mesh samples, named 
as $R_{C o n t r o l}, R_{F A}$, and $R_{A A}$, were conducted with enzymatic digestion. Prior to enzymatic hydrolysis, the possible structural changes of the cellulose surface were removed by an aqueous dilute acid $\left(1 \% \mathrm{H}_{2} \mathrm{SO}_{4}\right)$ at a mild temperature $\left(120^{\circ} \mathrm{C}\right)$ for $2 \mathrm{~h}$. The residues after dilute acid treatment were named as $\mathrm{R}_{\mathrm{H}-\mathrm{FA}}$ and $\mathrm{R}_{\mathrm{H}-\mathrm{AA}}$. The residues with and without dilute acid treatment were separately dispersed in sodium acetate buffer $(50 \mathrm{mM}, \mathrm{pH} 4.8)$ with a $2 \%$ substrate concentration. Cellulase (Cellic@ CTec2, 100 FPU/g) was added into the suspension with a loading of 15 FPU/g substrates, prior to incubating in a shaker (150 rpm) (DZH-2102, Jinghong, Shanghai, China) at $50{ }^{\circ} \mathrm{C}$ for $48 \mathrm{~h}$. During the process, the hydrolysates were termly sampled ( 24 and $48 \mathrm{~h}$ ) and analyzed by High Performance Anion Exchange Chromatography (HPAEC, Dionex, ICS 5000, USA), and the detailed method is shown in the supporting information. The enzymatic hydrolysis was performed in duplicate.

\subsection{Characterization of the Lignin Samples}

The molecular weight $\left(M_{w}\right.$ and $\left.M_{n}\right)$ and the polydispersity index $\left(M_{w} / M_{n}\right)$ of the stabilized lignin samples isolated from poplar wood (40-60 meshed and ball-milled poplar wood) based on different stabilization strategies (formaldehyde and acetaldehyde) were detected by gel permeation chromatography (GPC, Agilent 1200, USA) with a PL-gel $10 \mathrm{~mm}$ Mixed-B, $7.5 \mathrm{~mm}$ identity column, and an ultraviolet detector (UV, $240 \mathrm{~nm}$ ), which were calibrated with PL polystyrene standards with molecular weights of 1390, 4830, 9970, 29,150 and 69,650 g/mol. Generally, $2 \mathrm{mg}$ lignin was completely dissolved in $1 \mathrm{~mL}$ tetrahydrofuran (THF) and then filtered through a $0.22 \mu \mathrm{m}$ organic filter (Jinteng, Tianjin; diameter, $13 \mathrm{~mm}$; aperture pore, $0.22 \mu \mathrm{m}$; texture, Polytetrafluoroethylene (PTFE)). The column was operated at ambient temperature and eluted with THF at a flow rate of $1 \mathrm{~mL} / \mathrm{min}$.

The crystallinity index (CrI) of raw wood fibers and cellulose-rich residues was determined with an X-ray diffractometer. The Segal method was adopted to calculate the results [31]. The equation is as follows:

$$
\operatorname{CrI}(\%)=\left(\frac{\operatorname{I002}-\mathrm{Iam}}{\mathrm{I002}}\right) \times 100
$$

where I002 is the intensity of the (002) lattice diffraction at $2 \theta$ and approximately equals $22^{\circ}$, which represents the diffraction intensity of the crystallizing area, and Iam is the peak intensity of the amorphous area in cellulose at $2 \theta$ closing to $16^{\circ}$.

The chemical composition ratio and distribution of linkages in the stabilized lignin samples were quantified by heteronuclear single quantum coherence (2D-HSQC) with $50 \mathrm{mg}$ lignin dissolved in $0.5 \mathrm{~mL}$ DMSO-d6 [28]. The parameters of the 2D-HSQC sequence were used as follows: the pulse angle $\left(30^{\circ}\right)$, delay time (2 s), and number of scans (64). Functional groups of the lignin samples were determined by phosphorus spectrum nuclear magnetic resonance $\left({ }^{31} \mathrm{P}-\mathrm{NMR}\right.$ spectra) according to some previous publications [32,33].

\subsection{Analysis of Lignin Monomers}

The monomers obtained from the stabilized lignin preparations under different catalytic conditions were detected and analyzed by the GC-MS technique. In detail, the resulting liquid (Section 2.3) was filtrated with an organic strainer and then sampled for monomer analysis. The liquid was analyzed with GC-MS (Shimadzu GCMS-QP2010SE) equipped with an SH-Rxi-5SilMS (30 m length $\times 250 \mu \mathrm{m}$ I.D. $\times 0.25 \mu \mathrm{m}$ film thickness, Shimadzu) capillary column in GC, a secondary electron multiplier tube, and a high-precision metal quadrupole rod in MS. The injection temperature was $250^{\circ} \mathrm{C}$. The column temperature program was: $50{ }^{\circ} \mathrm{C}(3 \mathrm{~min}), 3{ }^{\circ} \mathrm{C} / \mathrm{min}$ to $230{ }^{\circ} \mathrm{C}$, and $10{ }^{\circ} \mathrm{C} / \mathrm{min}$ to $280{ }^{\circ} \mathrm{C}(3 \mathrm{~min})$. The standard sample of monomers was dissolved with the same solvent at a different concentration, analyzed by GC-MS at the uniform condition to obtain the standard curve as previously [34]. Finally, the yields of monomers were calculated based on the standard curve. 


\section{Results and Discussion}

In general, the direct catalytic degradation of native lignin in lignocellulose resulted in a high yield of lignin monomers [20,35]. However, the subsequent conversion of the substrate after lignin-first biomass fractionation has only been reported occasionally. The question of how to achieve the value-added applications of the cellulose-rich substrate after catalytic depolymerization became a new issue in this aspect [25]. Generally, $\beta-O-4$ linkage of lignin is a key to achieve monomer production during the degradation process $[25,36]$. In the first step of the present study, the aldehydes-stabilized lignin fractions were prepared and the detailed structural characteristics of the lignin were investigated. The better understanding of the molecular structures of lignin isolated during the lignin-first biomass fractionation will be beneficial for revealing the effects of different protection strategies on the production of lignin monomers and glucose for energy production.

\subsection{Structural Characteristics of the Control and Stabilized Lignin}

The detailed extraction conditions and characteristics of the aldehydes-stabilized lignin samples obtained from different conditions are shown in Table 1. After the different pretreatment conditions, it was observed that the yield of lignin fractions was ranged from $65.7 \%$ to $86.5 \%$, which had been corrected to exclude the impact of the attached aldehydes according to a previous report [37]. In detail, the $\mathrm{L}_{\text {Control }}$ (entry 1) obtained from 40-60 meshed poplar wood without the addition of aldehydes exhibited the lowest lignin yield (65.7\%). However, the lignin yields were increased to $68.0 \%$ and $85.1 \%$ based on the total content of lignin in 40-60 meshed poplar wood when the formaldehyde and acetaldehyde, respectively, served as protective agents. Alternatively, when 40-60 meshed poplar wood was substituted by ball-milled poplar wood, the corresponding extracting yields of $\mathrm{L}_{\mathrm{BM}}$ ( $\mathrm{L}_{\mathrm{BM} \text {-Control, }}$ $\mathrm{L}_{\mathrm{BM}-\mathrm{FA}}$, and $\mathrm{L}_{\mathrm{BM}-\mathrm{AA}}$ ) were increased to $78.0 \%, 82.5 \%$, and $86.5 \%$, respectively. As compared to the yield of $\mathrm{L}_{40-60}$, the increased yield of $\mathrm{L}_{\mathrm{BM}}$ was directly attributed to the high-contact area and high permeability of ball-milled polar wood powder with an extracting solvent. However, a high lignin yield does not ensure a high yield of lignin monomer products in the subsequent catalytic degradation of lignin, since structural features and the modification of the isolated lignin play a vital role in the catalytic degradation of lignin. In fact, the structural features of lignin are not only related to the biomass species and extracting method, but also affect the distribution and yields of lignin monomer products, based on a previous report [17].

Table 1. The characteristics of lignin fractions obtained under different conditions.

\begin{tabular}{|c|c|c|c|c|c|c|c|}
\hline & Entry & 1 & 2 & 3 & 4 & 5 & 6 \\
\hline & \multirow{2}{*}{$\begin{array}{c}\text { Lignin } \\
\left(\mathrm{L}_{40-60}, \mathrm{~L}_{\mathrm{BM}}\right)\end{array}$} & \multicolumn{3}{|c|}{$\mathrm{L}_{40-60}{ }^{\mathrm{a}}$} & \multicolumn{3}{|c|}{$\mathrm{L}_{B M}{ }^{a}$} \\
\hline & & $\mathrm{L}_{\text {Control }} \mathrm{b}$ & $L_{F A} b$ & $\mathrm{~L}_{\mathrm{AA}}{ }^{\mathrm{b}}$ & $\mathrm{L}_{\text {BM-Control }} \mathrm{b}$ & $L_{B M-F A}{ }^{b}$ & $\mathrm{~L}_{\mathrm{BM}-\mathrm{AA}}{ }^{\mathrm{b}}$ \\
\hline \multirow{4}{*}{ Characteristics $^{\mathrm{d}}$} & Yield" /\% & 65.7 & 68.0 & 85.1 & 78.0 & 82.5 & 86.5 \\
\hline & $\mathrm{M}_{\mathrm{W}}(\mathrm{g} / \mathrm{mol})$ & 1540 & 6580 & 4490 & 3160 & 6440 & 4840 \\
\hline & $\mathrm{M}_{\mathrm{n}}(\mathrm{g} / \mathrm{mol})$ & 750 & 2590 & 2100 & 1740 & 2540 & 2160 \\
\hline & $\mathrm{M}_{\mathrm{w}} / \mathrm{M}_{\mathrm{n}}$ & 2.05 & 2.54 & 2.14 & 1.82 & 2.54 & 2.24 \\
\hline
\end{tabular}

${ }^{a} \mathrm{~L}_{40-60}$, lignin obtained from $40-60$ meshed poplar wood; $\mathrm{L}_{\mathrm{BM}}$, lignin obtained from ball-milled poplar wood; ${ }^{\mathrm{b}}$ $\mathrm{L}_{\mathrm{Control}}$, lignin extracted from 40-60 meshed poplar wood without the addition of aldehydes; $\mathrm{L}_{\mathrm{FA}}$, lignin extracted from 40-60 meshed poplar wood with the presence of FA; $\mathrm{L}_{\mathrm{AA}}$, lignin extracted from 40-60 meshed poplar wood with the presence of AA, the same as $\mathrm{L}_{\mathrm{BM}-\mathrm{Control}}, \mathrm{L}_{\mathrm{BM}-\mathrm{FA}}$, and $\mathrm{L}_{\mathrm{BM}-\mathrm{AA}}$, except for the raw material (ball-milled poplar wood); ${ }^{c}$ Yield, based on the total lignin of poplar wood (corrected yield); ${ }^{\mathrm{d}}$ The GPC detection was performed in duplicate and the data reported were the average values.

Usually, it is expected that lignin with high $\beta-O-4$ contents can facilitate the subsequent depolymerization and upgrading of the lignin [38]. 2D-HSQC spectra of these lignin samples were performed to identify the detailed lignin structures, such as the $\mathrm{S} / \mathrm{G}$ ratio, the abundances of different linkages, and so on. The correlated signals in the 2D-HSQC spectra of $\mathrm{L}_{40-60}$ and $\mathrm{L}_{\mathrm{BM}}$ were 
assigned in supplementary materials-Table S1 based on recent publications [25,39]. For the control lignin fractions ( $\mathrm{L}_{\mathrm{Control}}$ and $\mathrm{L}_{\mathrm{BM}-\mathrm{Control}}$ ), the corresponding lignin linkages and chemical compositions are shown in Figures 1 and 2. The signal of $\mathrm{C}_{\gamma}-\mathrm{H}_{\gamma}$ in $\beta-O-4$ substructures $\left(\mathrm{A}_{\gamma}\right)$ was observable at $\delta_{C} / \delta_{H} 59.5 / 3.70$ and 3.56. The $C_{\alpha}-H_{\alpha}$ correlation in the $\beta-O-4$ substructures $\left(\mathrm{A}_{\alpha}\right)$ was visible at $\delta_{C} / \delta_{H}$ 71.7/4.85. Meanwhile, a signal located at $\delta_{C} / \delta_{\mathrm{H}} 64.1 / 4.47$ was attributed to the $\mathrm{C}_{\gamma}-\mathrm{H}_{\gamma}$ in $\gamma$-acylated $\beta$-O-4 substructures $\left(\mathrm{A}^{\prime} \gamma\right)$ by a $p$-hydroxybenzoic acid $(\mathrm{PB})$ unit, which is a special structural unit in poplar wood [40].
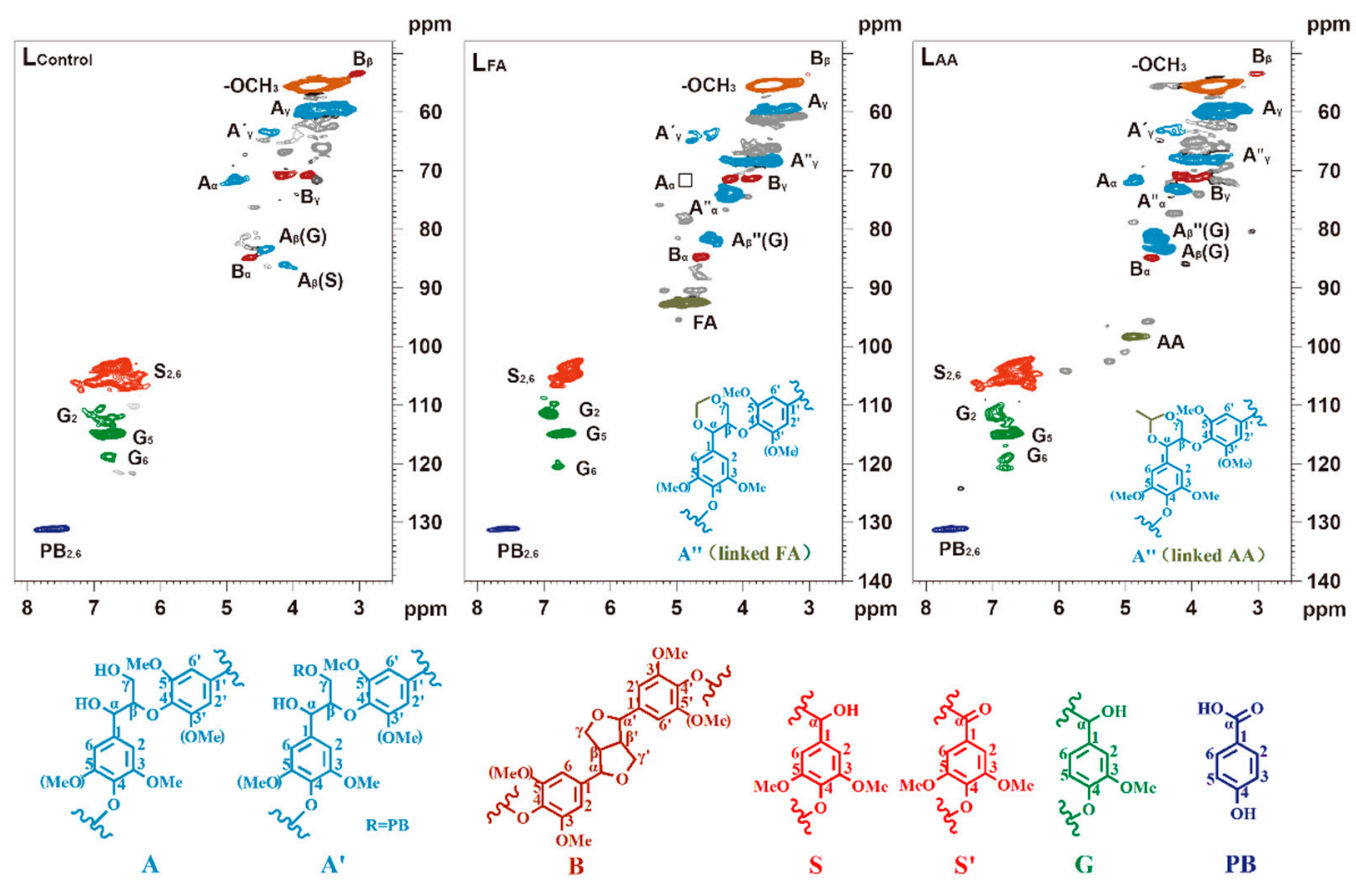

Figure 1. 2D-HSQC spectra of the lignin obtained from 40-60 meshed poplar wood and the main substructures. $\mathrm{L}_{\text {Control }}$ represents the lignin extracted from an acid solvent without the addition of aldehyde; $\mathrm{L}_{\mathrm{FA}}$ represents the lignin extracted with the presence of $F A$; $\mathrm{L}_{\mathrm{AA}}$ represents the lignin extracted with the presence of AA.

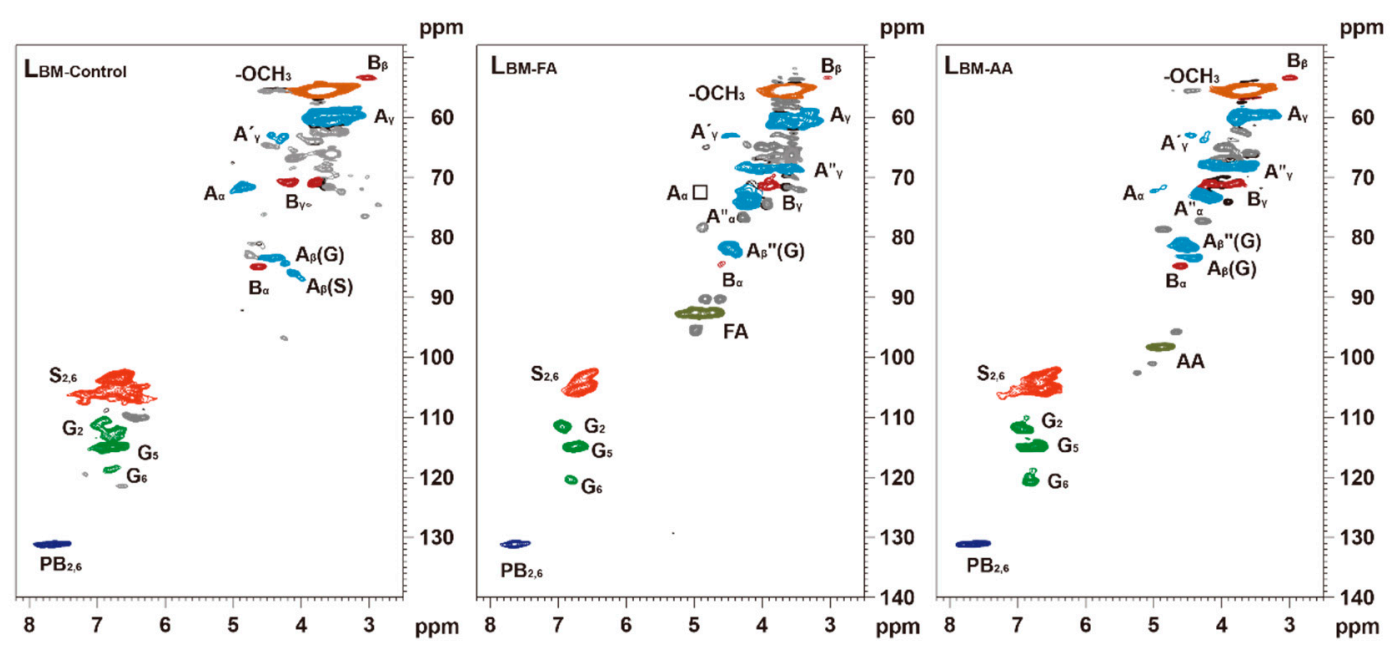

Figure 2. 2D-HSQC spectra of the lignin obtained from ball-milled poplar wood. $\mathrm{L}_{\mathrm{BM}-\mathrm{Control}}$ represents the lignin extracted from an acid solvent without the addition of aldehyde; $L_{B M-F A}$ represents the lignin extracted with the presence of FA; $\mathrm{L}_{\mathrm{BM}-\mathrm{AA}}$ represents the lignin extracted with the presence of AA. 
The $\mathrm{C}_{\beta}-\mathrm{H}_{\beta}$ correlations were observed at $\delta_{C} / \delta_{\mathrm{H}} 83.5 / 4.41$ and $86.0 / 4.12$ for $\beta-O-4$ substructures linked to the G and S units, respectively. However, the 2D-HSQC spectra of the lignin obtained in the presence of FA or AA presented a different chemical shift for all the $\mathrm{C}-\mathrm{H}$ correlations of $\beta-O-4$ linkage in lignin, which is in consensus with a previous report [25]. In detail, the 2D-HSQC spectra showed that the signals located at $\delta_{\mathrm{C}} / \delta_{\mathrm{H}} 68.2 / 3.99$ and 68.2/3.67 were assigned to the $\mathrm{C}_{\gamma}-\mathrm{H}_{\gamma}$ in shifted $\beta-O-4$ substructures $\left(\mathrm{A}^{\prime \prime}{ }_{\gamma}\right)$. The $\mathrm{A}^{\prime \prime}{ }_{\alpha}$ and $\mathrm{A}^{\prime \prime}{ }_{\beta}$ in the $2 \mathrm{D}-\mathrm{HSQC}$ spectra of $\mathrm{L}_{\mathrm{FA}}$ and $\mathrm{L}_{\mathrm{AA}}$ were respectively shifted to $\delta_{\mathrm{C}} / \delta_{\mathrm{H}} 73.4 / 4.24$ and 81.7/4.48. As compared to the spectrum of $\mathrm{L}_{\mathrm{FA}}$, the spectrum of $\mathrm{L}_{\mathrm{AA}}$ presented normal signals for $A_{\alpha}$ and $A_{\beta}(G)$, which were located at $\delta_{C} / \delta_{H} 71.7 / 4.85$ and 83.5/4.41, respectively. The appearance of these signals implied that the protecting reaction of lignin with AA was incomplete. Other frequent substructures, such as $-\mathrm{OCH}_{3}, \beta-\beta, S, G$, and $\mathrm{PB}$, were also observed in the spectra of $\mathrm{L}_{\mathrm{Control}}, \mathrm{L}_{\mathrm{FA}}$, and $\mathrm{L}_{\mathrm{AA}}$, based on a recent paper [28]. In short, the shifted signals were noticeable in the spectra of lignin extracted with the addition of FA and AA, suggesting that the formation of the ring structure (shown in supplementary materials-Figure S1) occurred during the lignin isolation process. Furthermore, the lignin ( $\mathrm{L}_{\mathrm{BM}-\mathrm{Control}}, \mathrm{L}_{\mathrm{BM}-\mathrm{FA}}$, and $\mathrm{L}_{\mathrm{BM}-\mathrm{AA}}$ ) extracted from ball-milled poplar wood displayed similar structural characteristics with $\mathrm{L}_{\mathrm{Control}}, \mathrm{L}_{\mathrm{FA}}$, and $\mathrm{L}_{\mathrm{AA}}$. The quantification of 2D-HSQC spectra of lignin preparations by signal integral was performed based on the computing method described in a previous publication [41] and the quantitative information on the structures of lignin are shown in Table 2. The S/G ratio of lignin can evaluate the chemical changes involved in the delignification process. In the present study, the $\mathrm{S} / \mathrm{G}$ ratios of $\mathrm{L}_{\mathrm{Control}}$ and $\mathrm{L}_{\mathrm{BM}-\mathrm{Control}}$ were 11.55 and 11.11, which were obviously higher than that (3.25) of the corresponding double enzymatic lignin (DEL), as previously reported [28], suggesting that the possible degradation of $G$ units occurred during the acidic extracting process without protection from aldehydes. However, the $\mathrm{S} / \mathrm{G}$ ratios of $\mathrm{L}_{\mathrm{FA}}$ and $\mathrm{L}_{\mathrm{BM}-\mathrm{FA}}$ were 2.49 and 2.79 , respectively, which was close to that of the corresponding DEL.

Table 2. Quantitative information on the structures of lignin from the 2D-HSQC spectra.

\begin{tabular}{|c|c|c|c|c|c|}
\hline \multirow{2}{*}{ Samples } & \multirow{2}{*}{$\mathrm{PB}_{2,6}$} & \multirow{2}{*}{ S/G } & \multirow{2}{*}{$\beta-\beta$} & \multicolumn{2}{|c|}{$\beta-O-4$} \\
\hline & & & & $\beta-O-4^{\prime b}$ & $\beta-O-4^{\prime \prime c}$ \\
\hline $\mathrm{L}_{\text {Control }}$ & 14.51 & 11.55 & 4.50 & 11.18 & $\mathrm{Tr}$ \\
\hline $\mathrm{L}_{\mathrm{FA}}$ & 13.99 & 2.49 & 16.46 & $\operatorname{Tr}^{\mathrm{a}}$ & 89.73 \\
\hline $\mathrm{L}_{\mathrm{AA}}$ & 11.52 & 5.62 & 5.46 & 9.98 & 30.26 \\
\hline $\mathrm{L}_{\mathrm{BM}-\mathrm{Control}}$ & 13.19 & 11.11 & 3.96 & 10.88 & $\operatorname{Tr}$ \\
\hline $\mathrm{L}_{\mathrm{BM}-\mathrm{FA}}$ & 10.53 & 2.79 & 0.96 & 4.52 & 76.49 \\
\hline $\mathrm{L}_{\mathrm{BM}-\mathrm{AA}}$ & 9.36 & 4.81 & 3.34 & 1.66 & 58.82 \\
\hline
\end{tabular}

a $\operatorname{Tr}, \operatorname{Trace}^{\mathrm{b}} \beta-O-4^{\prime}, \beta-O-4$ substructures in $\alpha$-position; $\beta-O-4^{\prime \prime},{ }^{c}$ the shifted $\beta-O-4$ substructures in $\alpha$-position.

As the most abundant linkage in the lignin, the content of $\beta-O-4$ linkage in lignin is positively correlated to the yield of lignin monomers [36]. In this study, compared with $\mathrm{L}_{\mathrm{FA}}, \mathrm{L}_{\mathrm{AA}}$ contained fewer $\beta-O-4$ linkages, and the $\beta-O-4$ linkages were presented in the form of normal and shifted substructures (labeled as $\beta-O-4^{\prime}$ and $\beta-O-4^{\prime \prime}$ ), revealing that the protection induced by acetaldehyde was weaker than that of formaldehyde, that is only a part of the lignin fraction formed ring structures with acetaldehyde. Compared with the content of $\beta-\beta$ in $\mathrm{L}_{\text {Control }}(4.50 / 100 \mathrm{Ar})$, the corresponding contents in $\mathrm{L}_{\mathrm{FA}}(16.46 / 100$ $\mathrm{Ar})$ and $\mathrm{L}_{\mathrm{AA}}(5.46 / 100 \mathrm{Ar})$ were apparently higher, due to the aldehyde protection, especially for formaldehyde. For the pendent unit, the contents of PB units in $\mathrm{L}_{\mathrm{FA}}(13.99 / 100 \mathrm{Ar})$ and $\mathrm{L}_{\mathrm{AA}}(11.52 / 100$ $\mathrm{Ar}$ ) were lower than that of $\mathrm{L}_{\mathrm{Control}}(14.51 / 100 \mathrm{Ar})$, implying that the aldehydes-aided lignin extraction process led to some cleavage of these units. Nevertheless, the content of PB in $\mathrm{L}_{\mathrm{BM}}$ was lower than those of corresponding $\mathrm{L}_{40-60}$, which was probably ascribed to the effect of the ball-milled process during the preparation of ball-milled poplar wood. In the view of energy consumption and structural changes, the lignin extracted from 40-60 meshed poplar wood was used as starting feedstock for further catalytic depolymerization. 
Quantitative ${ }^{31} \mathrm{P}-\mathrm{NMR}$ techniques can evaluate the functional groups of these lignin samples. In this study, the lignin samples obtained from 40-60 meshed poplar wood were detected by ${ }^{31} \mathrm{P}-\mathrm{NMR}$ and the corresponding spectra and quantitative data are shown in Figure 3 and Table 3. In detail, the contents of aliphatic $\mathrm{OH}$ groups in $\mathrm{L}_{\mathrm{FA}}, \mathrm{L}_{\mathrm{AA}}$, and $\mathrm{L}_{\mathrm{Control}}$ were, respectively, 1.14, 1.75, and $2.60 \mathrm{mmol} / \mathrm{g}$, suggesting that the aliphatic $\mathrm{OH}$ groups of lignin were occupied by aldehydes to some degree during lignin extraction processes. Especially, it was found that the $\mathrm{L}_{\mathrm{FA}}$ contained the fewest aliphatic $\mathrm{OH}$ groups $(1.14 \mathrm{mmol} / \mathrm{g})$, which testified that the effect of substitution and protection can be maximized by FA. Additionally, the carbohydrates in the lignin also contributed the aliphatic $\mathrm{OH}$ groups in the lignin. Meanwhile, compared with $\mathrm{L}_{\mathrm{Control}}$ and $\mathrm{L}_{\mathrm{AA}}, \mathrm{L}_{\mathrm{FA}}$ had fewer $\mathrm{S}$ - and G-type $\mathrm{OH}$ groups, indicating that the lignin $\mathrm{L}_{\mathrm{FA}}$ contained more content of $\beta$-O-4 linkages, thus the $\mathrm{S}$ - and G-type phenolic $\mathrm{OH}$ groups cannot be detected. Moreover, the condensed guaiacyl units can be observed in all the lignin samples. The addition of aldehydes can prevent the guaiacyl units in lignin from forming condensation under the acidic condition. For the $\mathrm{H}$-type phenolic $\mathrm{OH}$ group, it mainly originated from p-hydroxybenzoate $(\mathrm{PB})$ substructures. In short, the lignin preparations $\left(\mathrm{L}_{\mathrm{FA}}\right.$ and $\left.\mathrm{L}_{\mathrm{AA}}\right)$ were optimal lignin feedstock for further catalyzed degradation.

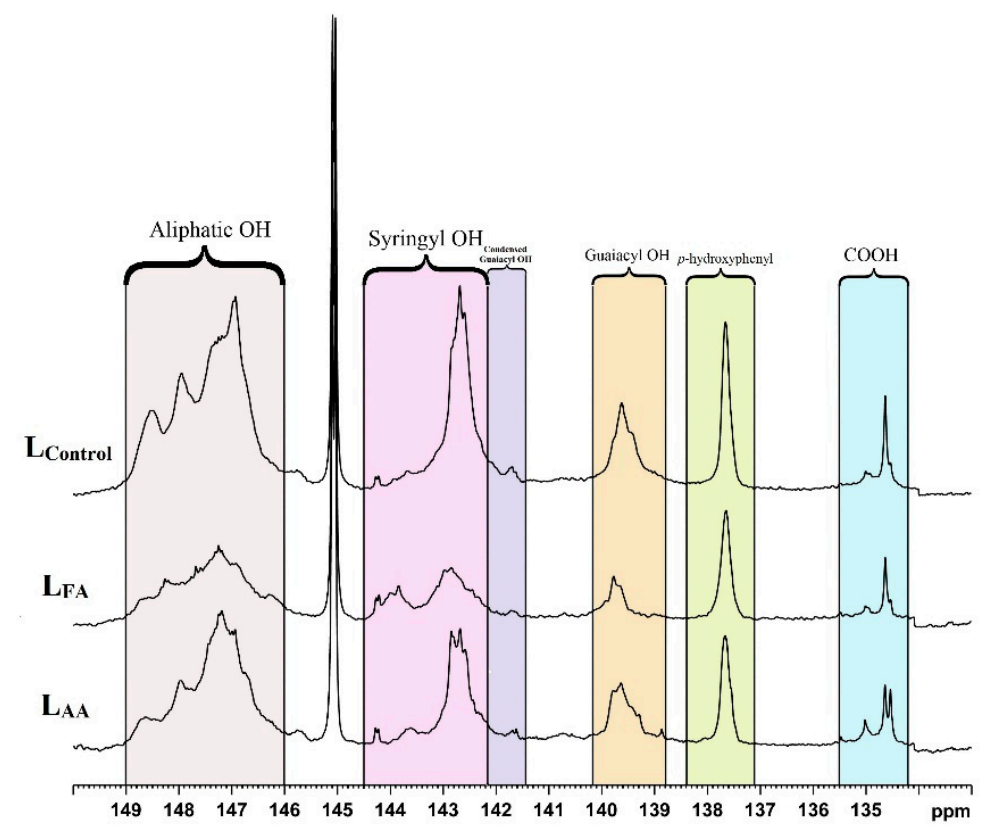

Figure 3. ${ }^{31} \mathrm{P}-\mathrm{NMR}$ spectra of the lignin polymers obtained by different conditions. All the lignin samples were obtained from 40-60 meshed poplar wood and extracted under conditions without aldehyde, with FA, and with AA.

Table 3. Quantification of different $\mathrm{OH}$ groups in the lignin fractions by ${ }^{31} \mathrm{P}-\mathrm{NMR}(\mathrm{mmol} / \mathrm{g})$.

\begin{tabular}{|c|c|c|c|c|c|c|}
\hline \multirow{2}{*}{ Samples } & \multirow{2}{*}{$\begin{array}{c}\text { Aliphatic } \\
\text { OH }\end{array}$} & \multirow{2}{*}{$\begin{array}{l}\text { Syringyl } \\
\mathrm{OH}\end{array}$} & \multicolumn{2}{|c|}{ Guaiacyl OH } & \multirow{2}{*}{$\begin{array}{c}\text { H-OH } \\
\text { (PB and/or H) }\end{array}$} & \multirow{2}{*}{$\begin{array}{l}\text { Carboxylic } \\
\text { group }\end{array}$} \\
\hline & & & $\mathrm{C}^{\mathrm{a}}$ & $N C^{b}$ & & \\
\hline $\mathrm{L}_{\text {Control }}$ & 2.60 & 1.15 & 0.14 & 0.49 & 0.40 & 0.19 \\
\hline $\mathrm{L}_{\mathrm{FA}}$ & 1.14 & 0.61 & 0.05 & 0.20 & 0.30 & 0.14 \\
\hline $\mathrm{L}_{\mathrm{AA}}$ & 1.75 & 0.78 & 0.10 & 0.41 & 0.30 & 0.19 \\
\hline
\end{tabular}

${ }^{\mathrm{a}}$ Condensed units; ${ }^{\mathrm{b}}$ Non-condensed units.

GPC analysis was performed to estimate the molecular weights of lignin obtained from different extracting conditions and the results are shown in Table 1. The molecular weight of $\mathrm{L}_{\mathrm{BM}}$ samples exhibited an analogical tendency with those of $\mathrm{L}_{40-60}$ preparations. For the lignin obtained from 40-60 meshed poplar wood, the $M_{w}$ of $\mathrm{L}_{\mathrm{FA}}(6580 \mathrm{~g} / \mathrm{mol})$ and $\mathrm{L}_{\mathrm{AA}}(4490 \mathrm{~g} / \mathrm{mol})$ were significantly higher than that of $\mathrm{L}_{\text {Control }}(1540 \mathrm{~g} / \mathrm{mol})$, implying that aldehydes protected the linkages from cleaving during 
dioxane extraction under acidic condition, which can also be further verified by the corresponding 2D-HSQC NMR spectra. Meanwhile, the $M_{w}$ of $L_{F A}$ was significantly higher than that of $\mathrm{L}_{\mathrm{AA}}$, which was likely related to the relatively high content of the $\beta-O-4$ linkage as a result of the better protection of formaldehyde. In addition, the modification of lignin with FA or AA also increased the $M_{w}$, and the degree of modification with formaldehyde was higher. $\mathrm{L}_{40-60}$ and the corresponding $\mathrm{L}_{\mathrm{BM}}$ fractions showed a similar $M_{w}, M_{n}$, and $M_{w} / M_{n}$, except for the control samples ( $\mathrm{L}_{\text {Control }}$ and $\mathrm{L}_{\mathrm{BM}-\mathrm{Control}}$ ).

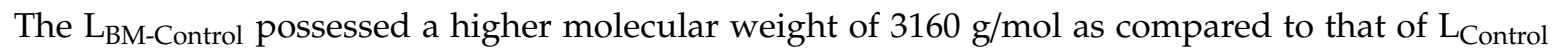
(1540 $\mathrm{g} / \mathrm{mol})$, which was attributed to the fact that ball-milled pretreatment facilitated the lignin isolation under the acidic condition. Meanwhile, the polydispersity index (PDI, $M_{w} / M_{n}$ ) of $\mathrm{L}_{\mathrm{BM} \text {-Control }}$ was 1.82, which was lower than that of $\mathrm{L}_{\text {Control }}(2.05)$, implying that $\mathrm{L}_{\mathrm{BM}-\mathrm{Control}}$ preparation was more homogeneous than that of $\mathrm{L}_{\mathrm{Control}}$.

\subsection{Hydrogenolysis of the Extracted Lignin Feedstock}

To understand the effects of the lignin structure and catalytic degradation system on the hydrogenolysis reactions of lignin, the types and content of the degraded products of $\mathrm{L}_{\mathrm{Control}}$, $\mathrm{L}_{\mathrm{FA}}$, and $\mathrm{L}_{\mathrm{AA}}$ under the given conditions were analyzed by the GC-MS technique. Figure 4 and supplementary materials-Figure S2 show the detailed degraded monomers and the distribution GC-MS spectra of the degraded lignin products. It was observed that all the degraded monomers belonged to G- and S-type aromatic monomers and the product selectivity was acceptable in all the experiments, especially for the degraded lignin monomers that originated from $\mathrm{L}_{\mathrm{FA}}$ with the THF and $\mathrm{MeOH}$ degradation systems. As shown in Figure 5, 2,6-dimethoxy-4-propylphenol (component 6, dark blue) and 3-(4-hydroxy-3,5- dimethoxy-phenyl)-propionaldehyde (component 7, purple) were the main compounds of hydrogenolysis in all the experiments, and other minor aromatic monomers were also found and marked with diverse colors. Based on the main components of the degraded products, it can be concluded that the catalytic degradation systems showed excellent selectivity for degraded products and a low ring-hydrogenation activity. In the present study, the lignin monomers in the organic phase were identified via GC-MS and the quantification was determined by authentic samples. The hydrogenolysis of different lignin preparations $\left(\mathrm{L}_{\mathrm{Control}}, \mathrm{L}_{\mathrm{FA}}\right.$, and $\mathrm{L}_{\mathrm{AA}}$ ) under the same condition generated several lignin monomers, with a combined yield of 16.55 to $42.57 \mathrm{wt} \%$ (see supplementary materials-Table S2). It was found that the $\mathrm{L}_{\mathrm{FA}}$ degraded in THF presented the highest monomer yield, which agrees with a recent study [25]. However, when the solvent of THF was substituted by MeOH and dioxane, the total yield of monomers decreased from $42.57 \%$ to $33.07 \%$ and $26.58 \mathrm{wt} \%$, respectively.

The highest yield of monomers in THF was probably ascribed to many factors, such as the dissolution of lignin, polar, and the $\mathrm{pH}$ value of the solvent applied [42]. However, when the hydrogenolysis of lignin $\left(\mathrm{L}_{\mathrm{FA}}, \mathrm{L}_{\mathrm{AA}}\right.$, and $\mathrm{L}_{\text {Control }}$ ) was performed in THF under the same condition (entries B, C, and A), the total yield of monomers was $42.57 \%, 33.00 \%$, and $16.55 \%$, respectively. These results indicated that the addition of aldehyde remarkably facilitated the subsequent hydrogenolysis of the extracted lignin, especially for $\mathrm{L}_{\mathrm{FA}}$. In fact, the sufficient reaction between formaldehyde and lignin generated the lignin with a non-condensed structure, and was also beneficial to the downstream catalytic degradation process [25]. In addition to the total yield of all the monomers, the selectivity of the main monomers is another factor that needs to be considered. In this study, the content of the main monomers (6 and 7) varied with different experimental entries (Table S2). For example, the selectivity of component 6 was $39.93 \%$, based on the total yield of degraded monomers in entry B ( $\mathrm{L}_{\mathrm{FA}}$ in THF), while the value was decreased to $32.69 \%$ in entry D. By contrast, the selectivity of component 6 was $46.61 \%$ in entry $\mathrm{C}\left(\mathrm{L}_{\mathrm{AA}}\right.$ in $\left.\mathrm{THF}\right)$. This fact indicated that not only the degradation system but also the lignin feedstock affected the yields and selectivity of aromatic monomers. In short, a more detailed monomer distribution, such as retention time in GC-MS, compounds, and corresponding structures for all experiments is presented in supplementary materials-Table S3. 


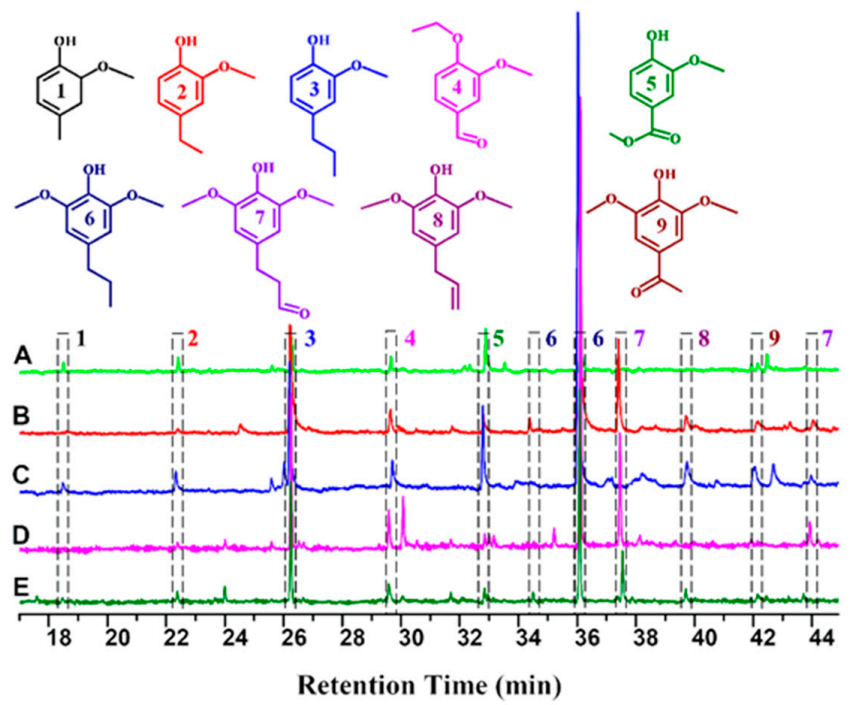

Figure 4. GC-MS chromatogram of the lignin monomers obtained from the degradation of different lignin samples and solvent systems. (A) $\mathrm{L}_{\text {Control }}$ degraded in THF as the solvent system. (B) $\mathrm{L}_{\mathrm{FA}}$ degraded in THF as the solvent system. (C) $\mathrm{L}_{\mathrm{AA}}$ degraded in THF as the solvent system. (D) $\mathrm{L}_{\mathrm{FA}}$ degraded in $\mathrm{MeOH}$ as the solvent system. (E) $\mathrm{L}_{\mathrm{FA}}$ degraded in dioxane as the solvent system.

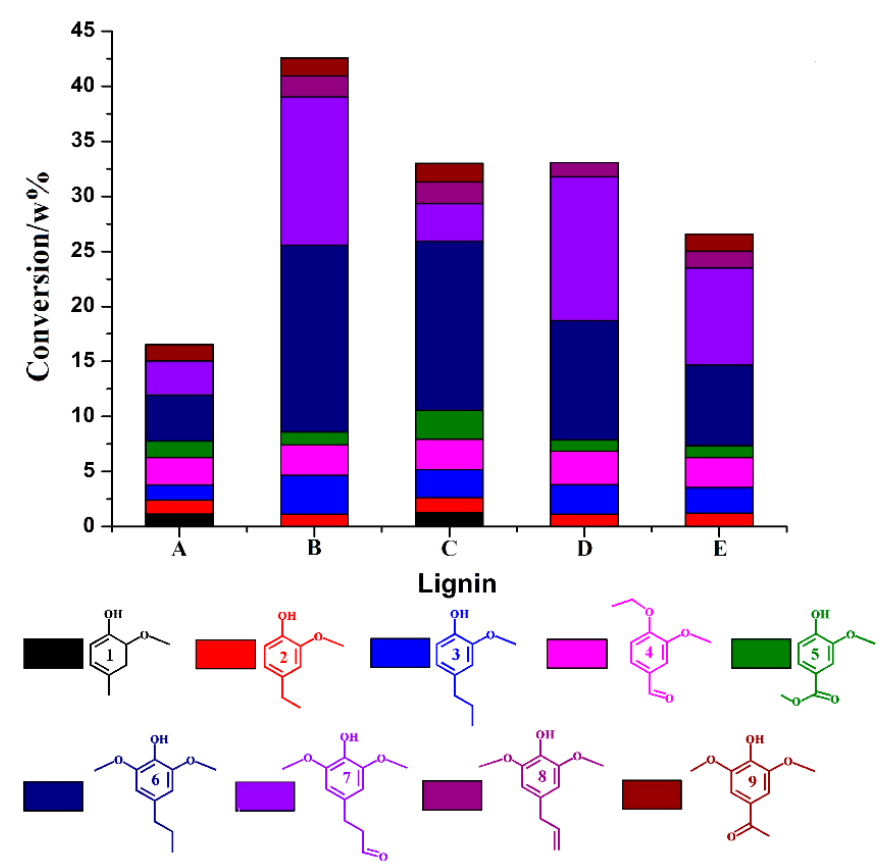

Figure 5. Production of lignin monomers obtained from different lignin samples and solvent systems. Y: Lignin monomer yields from 40-60 meshed poplar wood. X: (A) $\mathrm{L}_{\text {Control }}$ degraded in THF as the solvent system. (B) $\mathrm{L}_{\mathrm{FA}}$ degraded in THF as the solvent system. (C) $\mathrm{L}_{\mathrm{AA}}$ degraded in THF as the solvent system. (D) $\mathrm{L}_{\mathrm{FA}}$ degraded in $\mathrm{MeOH}$ as the solvent system. (E) $\mathrm{L}_{\mathrm{FA}}$ degraded in dioxane as the solvent system.

The monomer products disassembled from lignin were promising chemicals and fuel components. More importantly, some of them could not be easily synthesized. Firstly, the aromatic monomer could be utilized as platform chemicals. Secondly, the lignin monomers could be further converted to aniline derivatives via dehydrogenation and amination reactions, which are chemicals suited for accomplishing transformations toward value-added products [43]. Finally, these monomers could be applied as polymer building blocks, such as epoxy thermosets, polycarbonates, cyanate ester resins, 
and emerging diverse bio-based polymers [44]. Of course, further applications of these degradation products are currently being investigated.

\subsection{Enzymatic Hydrolysis of the Substrates after Lignin-first Deconstruction Strategy}

Recent studies have demonstrated that ideal pretreatment should maximize the lignin removal or delocalization and minimize polysaccharide modification [45,46]. In this study, the lignin-first biomass fractionation was applied to protectively extract lignin and overcome biomass recalcitrance to release glucose by enzymatic hydrolysis. In addition to the content and structure of lignin and carbohydrates, the crystallinity index was also used to evaluate the existing form of cellulose in the substrates, although the crystallinity index (CrI) was not an important factor contributing to subsequent enzymatic digestibility as generally believed [47]. In this study, the CrI (supplementary materials-Figure S3) of the different substrates showed that the raw material had the highest CrI, while the $\mathrm{CrI}$ of the substrates after lignin-first biomass fractionation decreased to different extents. This further suggested that the crystalline cellulose was depolymerized under the acidic condition.

Regarding the conversion rate of cellulose into glucose in the substrates, as shown in Figure 6, the yield of glucose reached up to $61.40 \%$ for the control sample $\left(\mathrm{R}_{\text {Control }}\right)$. The highest yield of glucose (85.14\%) was obtained from the enzymatic hydrolysis of $\mathrm{R}_{\mathrm{H}-\mathrm{AA}}$, which represented the substrate that underwent further dilute acid treatment. By contrast, although the FA-treated substrates removed grafted FA on the surface with $1 \mathrm{wt} \% \mathrm{H}_{2} \mathrm{SO}_{4}$, the final yield of glucose from $\mathrm{R}_{\mathrm{FA}}$ was only increased from $15.40 \%$ to $30.38 \%$ in $\mathrm{R}_{\mathrm{H}-\mathrm{FA}}$, which was still significantly lower than that of AA-treated substrates $\left(\mathrm{R}_{\mathrm{H}-\mathrm{AA}}\right.$ and $\left.\mathrm{R}_{\mathrm{AA}}\right)$ in this study. Generally, the substrate with a high delignification ratio had a high enzymatic hydrolysis of cellulose. A recent report has also demonstrated that the glucose yield of $R_{\mathrm{FA}}$ obviously increased after the treatment with the dilute acid solution [25]. However, even if no dilute acid treatment was applied to the AA-treated substrate in this study, its glucose yield also reached up to $75.12 \%$. Our results are in agreement with the results presented in a recently published article regarding the "protective" extraction of lignin and hydrogenolysis, in which the recovery yield of polysaccharides (glucan and xylan) was more than $75 \%$ [26]. Considering the yield of lignin monomers and glucose, it was concluded that the lignin-first deconstruction strategy with the addition of AA could facilitate the production of lignin monomers with a higher yield and selectivity as well as a high yield of glucose.

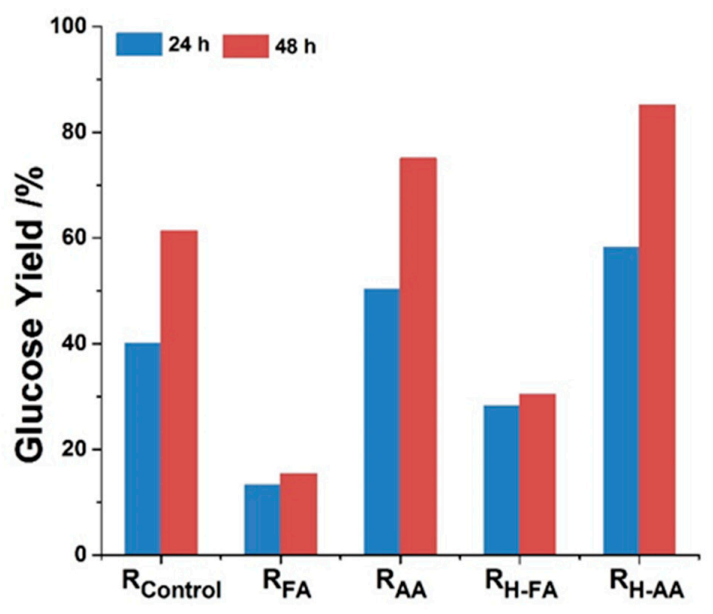

Substrate

Figure 6. The glucose yield of the substrates after lignin extraction. (H-FA and H-AA were treated by additional acid: $120{ }^{\circ} \mathrm{C}, 2 \mathrm{~h}, 1 \mathrm{wt} \% \mathrm{H}_{2} \mathrm{SO}_{4}$ solution; liquid/solid: 10:1 v/w; enzymatic hydrolysis conditions: concentration of substrate: $5 \% ; 50{ }^{\circ} \mathrm{C} ; 250 \mathrm{rpm}$; and enzyme (Novozymes Cellic ${ }^{\circledR}$ ctec2) loading of $15 \mathrm{FPU} / \mathrm{g}$ substrates). 


\subsection{A Proposed Biorefinery Scheme Focused on the Production of Lignin Monomer and Glucose}

In the present study, the lignin-first biomass deconstruction and upgrading process could be easily integrated into the current biorefinery paradigm. However, compared with FA, AA is a more promising chemical due to the following reasons. Firstly, AA is a more environmentally friendly reagent than FA. Secondly, an AA-treated substrate is more prone to be degraded by enzymatic hydrolysis as compared to an FA-treated substrate. Thirdly, although the yield of lignin monomers from $\mathrm{L}_{\mathrm{AA}}(33.00 \%)$ is lower than that of $\mathrm{L}_{\mathrm{FA}}(42.57 \%)$, the selectivity of the leading lignin monomer (component 6) from $\mathrm{L}_{\mathrm{AA}}$ in the THF solution is higher $(46.61 \%)$ than that $(39.93 \%)$ of $\mathrm{L}_{\mathrm{FA}}$. Considering the high cost $(\$ 46,260 / \mathrm{g}$, standard sample, from Shanghai Fusheng Industrial Co. LTD, http://www.affandi-e.com/) of the main degraded component 2,6-dimethoxy-4-propylphenol (component 6), the high yield (15.38\%, SI) and glucose will maximize the valorization of the biomass. It should be noted that the reagent and solvents used in the study can be recycled, which can obviously reduce the cost of pretreatment. In short, considering the value of the final products, environmental benefits, and dilute acid treatment, the AA-aided biorefinery scheme without ultimate acid treatment would be optimal to produce lignin monomers and glucose for bioethanol production in the current bio-based chemicals and energy production.

\section{Conclusions}

With the addition of a protective agent, the lignin-first biomass deconstruction strategy yielded easily degradable lignin fractions with uncondensed and stable structures and digestible cellulose, facilitating the conversion of lignin and carbohydrates into lignocelluloses. Under the optimized condition (in the presence of acetaldehyde, AA), the relatively high yields of lignin monomers $(33.00 \%)$ and glucose $(75.12 \%)$ were obtained. Additionally, the selectivity $(46.61 \%)$ of lignin monomer (2,6-dimethoxy-4-propylphenol) from $\mathrm{L}_{\mathrm{AA}}$ was higher than that (39.93\%) of $\mathrm{L}_{\mathrm{FA}}$. In short, the AA-aided lignin-first biomass deconstruction is beneficial for promoting the production of lignin monomer and fermentable glucose in an efficient approach, and for providing an alternative route to support sustainable energy and chemical production.

Supplementary Materials: The following are available online at http:/www.mdpi.com/1996-1073/13/5/1113/s1. Materials and method used in this paper, The calculation of correction yield of lignin, Table S1: Assignments of ${ }^{13} \mathrm{C}-{ }^{1} \mathrm{H}$ cross signals in the HSQC spectra of lignin obtained from different conditions, Table S2: Detailed yields of the main aromatic products from the lignin depolymerization reaction over different conditions (based on the weight of starting lignin), Table S3: The main components of the degraded products, Table S4: The composition analysis of the control and delignified substrates under different conditions, Table S5: The glucose yield of the substrates after lignin extraction, Figure S1: The chemical reaction that occurs between aldehydes (formaldehyde and acetaldehyde) and $\alpha$-and $\gamma-\mathrm{OH}$ in the side chain of lignin, Figure S2: GC-MS chromatographic of the products obtained from the degradation of different lignin samples and solvent systems. (A) $\mathrm{L}_{\mathrm{C} \text { control }}$ degraded in THF as the solvent system. (B) $\mathrm{L}_{\mathrm{FA}}$ degraded in THF as the solvent system. (C) $\mathrm{L}_{\mathrm{AA}}$ degraded in THF as the solvent system. (D) $\mathrm{L}_{\mathrm{FA}}$ degraded in $\mathrm{MeOH}$ as the solvent system. (E) $\mathrm{L}_{\mathrm{FA}}$ degraded in dioxane as the solvent system. Figure S3: XRD spectra of the raw material and treated substrates.

Author Contributions: Conceptualization, T.-Y.C. and J.-L.W.; Data curation, C.-Y.M., S.-N.S., X.-F.C., and T.-Q.Y.; Formal analysis, T.-Y.C. and C.-Y.M.; Funding acquisition, J.-L.W.; Investigation, T.-Y.C.; Methodology, T.-Y.C.; Project administration, J.-L.W. and R.-C.S.; Resources, D.-Y.M., C.-F.L., J.-L.W., T.-Q.Y., and R.-C.S.; Supervision, J.-L.W.; Validation, T.-Y.C. and J.-L.W.; Visualization, T.-Y.C.; Writing-original draft, T.-Y.C.; Writing-review and editing, J.-L.W. All authors have read and agreed to the published version of the manuscript.

Funding: This research was funded by National Natural Science Foundation of China [31872698], Beijing Forestry University Outstanding Young Talent Cultivation Project [2019JQ03006, 2019JQ03005], Open Foundation of Guangxi Key Laboratory of Clean Pulp and Papermaking and Pollution Control [KF201714], Open Foundation of the State Key Laboratory of Pulp and Paper Engineering [201749], and National Key Research and Development Program of China [2019YFB1503801].

Conflicts of Interest: No conflict of interest exits in the submission of this manuscript, and the manuscript was approved by all authors for publication. The founding sponsors had no role in the design of the study; in the collection, analyses, or interpretation of data; in the writing of the manuscript, and in the decision to publish the results. 


\section{References}

1. Sagues, W.J.; Bao, H.X.; Nemenyi, J.L.; Tong, Z. Lignin-First Approach to Biorefining: Utilizing Fenton's Reagent and Supercritical Ethanol for the Production of Phenolics and Sugars. ACS Sustain. Chem. Eng. 2018, 6, 4958-4965. [CrossRef]

2. Agarwal, A.; Rana, M.; Park, J.H. Advancement in technologies for the depolymerization of lignin. Fuel Process. Technol. 2018, 181, 115-132. [CrossRef]

3. Schutyser, W.; Renders, T.; Bosch, S.V.; Koelewijn, S.F.; Beckham, G.T.; Sels, B.F. Chemicals from lignin: an interplay of lignocellulose fractionation, depolymerisation, and upgrading. Chem. Soc. Rev. 2018, 47, 852-908. [CrossRef]

4. $\quad$ Renders, T.; Bosch, S.V.; Koelewijn, S.F.; Schutyser, W.; Sels, B.F. Lignin-first biomass fractionation: the advent of active stabilisation strategies. Energy Environ. Sci. 2017, 10, 1551-1557. [CrossRef]

5. Yu, I.K.M.; Tsang, D.C.W. Conversion of biomass to hydroxymethylfurfural: A review of catalytic systems and underlying mechanisms. Bioresour. Technol. 2017, 238, 716-732. [CrossRef] [PubMed]

6. Huang, C.X.; Jeuck, B.; Du, J.; Yong, Q.; Chang, H.M.; Jameel, H.; Phillips, R. Novel process for the coproduction of xylo-oligosaccharides, fermentable sugars, and lignosulfonates from hardwood. Bioresour. Technol. 2016, 219, 600-607. [CrossRef]

7. Jin, Y.C.; Jameel, H.; Chang, H.M.; Phillips, R. Green liquor pretreatment of mixed hardwood for ethanol production in a repurposed kraft pulp mill. J. Wood Chem. Technol. 2010, 30, 86-104. [CrossRef]

8. Li, Y.D.; Shuai, L.; Kim, H.; Motagamwala, A.H.; Mobley, J.K.; Yue, F.X.; Luterbacher, J.S. An “ideal lignin” facilitates full biomass utilization. Sci. Adv. 2018, 4, eaau2968. [CrossRef]

9. Ma, Z.Q.; Wang, J.H.; Zhou, H.Z.; Zhang, Y.; Yang, Y.Y.; Liu, X.H.; Ye, J.W.; Chen, D.Y.; Wang, S.R. Relationship of thermal degradation behavior and chemical structure of lignin isolated from palm kernel shell under different process severities. Fuel Process. Technol. 2018, 181, 142-156. [CrossRef]

10. Liu, C.; Wang, X.; Lin, F.; Zhang, H.; Xiao, R. Structural elucidation of industrial bioethanol residual lignin from corn stalk: A potential source of vinyl phenolics. Fuel Process. Technol. 2018, 169, 50-57. [CrossRef]

11. Cordella, M.; Torri, C.; Adamiano, A.; Fabbri, D.; Barontini, F.; Cozzani, V. Bio-oils from biomass slow pyrolysis: a chemical and toxicological screening. J. Hazard. Mater. 2012, 231, 26-35. [CrossRef] [PubMed]

12. Wang, T.; Ye, X.; Yin, J.; Jin, Z.; Lu, Q.; Zheng, Z.; Dong, C. Fast pyrolysis product distribution of biopretreated corn stalk by methanogen. Bioresour. Technol. 2014, 169, 812-815. [CrossRef]

13. Qu, Y.; Wang, Z.; Lu, Q.; Zhang, Y. Selective production of 4-vinylphenol by fast pyrolysis of herbaceous biomass. Ind. Eng. Chem. Res. 2013, 52, 12771-12776. [CrossRef]

14. Ralph, J.; Lundquist, K.; Brunow, G.; Lu, F.; Kim, H.; Schatz, P.F.; Boerjan, W. Lignins: natural polymers from oxidative coupling of 4-hydroxyphenyl-propanoids. Phytochem. Rev. 2004, 3, 29-60. [CrossRef]

15. Wen, J.L.; Sun, S.N.; Yuan, T.Q.; Xu, F.; Sun, R.C. Fractionation of bamboo culms by autohydrolysis, organosolv delign.ification and extended delignification: understanding the fundamental chemistry of the lignin during the integrated process. Bioresour. Technol. 2013, 150, 278-286. [CrossRef] [PubMed]

16. Liu, C.; Wu, S.; Zhang, H.; Xiao, R. Catalytic oxidation of lignin to valuable biomass-based platform chemicals: a review. Fuel Process. Technol. 2019, 191, 181-201. [CrossRef]

17. Rinaldi, R.; Jastrzebski, R.; Clough, M.T.; Ralph, J.; Kennema, M.; Bruijnincx, P.C.; Weckhuysen, B.M. Paving the Way for Lignin valorisation: Recent advances in bioengineering, biorefining and catalysis. Angew. Chem. Int. Engl. 2016, 55, 8164-8215. [CrossRef]

18. Lan, W.; Luterbacher, J.S. Preventing Lignin Condensation to Facilitate Aromatic Monomer Production. CHIMIA Int. J. Chem. 2019, 73, 591-598. [CrossRef]

19. Shuai, L.; Saha, B. Towards high-yield lignin monomer production. Green Chem. 2017, 19, 3752-3758. [CrossRef]

20. Bosch, S.V.; Schutyser, W.; Vanholme, R.; Driessen, T.; Koelewijn, S.F.; Renders, T.; Meester, B.D.; Huijgen, W.; Dehaen, W.; Courtin, C. Reductive lignocellulose fractionation into soluble lignin-derived phenolic monomers and dimers and processable carbohydrate pulps. Energy Environ. Sci. 2015, 8, 1748-1763. [CrossRef]

21. Chen, L.; Dou, J.; Ma, Q.; Li, N.; Wu, R.; Bian, H.; Yelle, D.J.; Vuorinen, T.; Fu, S.; Pan, X.J.; et al. Rapid and near-complete dissolution of wood lignin at $\leq 80$ degrees $C$ by a recyclable acid hydrotrope. Sci. Adv. 2017, 3, e1701735. [CrossRef] 
22. Shuai, L.; Sitison, J.; Sadula, S.; Ding, J.; Thies, M.C.; Saha, B. Selective C-C bond cleavage of methylene-linked lignin models and kraft lignin. ACS Catal. 2018, 8, 6507-6512. [CrossRef]

23. Avelino, F.; Silva, K.T.; Filho, M.S.M.; Mazzetto, S.E.; Lomonaco, D. Microwave-assisted organosolv extraction of coconut shell lignin by Brønsted and Lewis acids catalysts. J. Clean. Prod. 2018, 189, 785-796. [CrossRef]

24. Lou, R.; Ma, R.; Lin, K.T.; Ahamed, A.; Zhang, X. Facile extraction of wheat straw by deep eutectic solvent (des) to produce lignin nanoparticles. ACS Sustain. Chem. Eng. 2019, 7, 10248-10256. [CrossRef]

25. Shuai, L.; Amiri, M.T.; Questell-Santiago, Y.M.; Héroguel, F.; Li, Y.; Kim, H.; Meilan, R.; Chapple, C.; Ralph, J.; Luterbacher, J.S. Formaldehyde stabilization facilitates lignin monomer production during biomass depolymerization. Science 2016, 354, 329-333. [CrossRef]

26. Lan, W.; Amiri, M.T.; Hunston, C.M.; Luterbacher, J. Protection Group Effects during $\alpha, \gamma$-Diol Lignin Stabilization Promote High-Selectivity Monomer Production. Angew. Chem. 2018, 57, 1356-1360. [CrossRef]

27. Luterbacher, J.S.; Azarpira, A.; Motagamwala, A.H.; Lu, F.; Ralph, J.; Dumesic, J.A. Lignin monomer production integrated into the g-valerolactone sugar platform. Energy Environ. Sci. 2015, 8, 2657-2663. [CrossRef]

28. Chen, T.Y.; Wang, B.; Shen, X.J.; Li, H.Y.; Wu, Y.Y.; Wen, J.L.; Liu, Q.Y.; Sun, R.C. Assessment of structural characteristics of regenerated cellulolytic enzyme lignin based on a mild DMSO/[Emim]OAc dissolution system from triploid of Populus tomentosa Carr. RSC Adv. 2017, 7, 3376-3387. [CrossRef]

29. Wen, J.L.; Xue, B.L.; Xu, F.; Sun, R.C.; Pinkert, A. Unmasking the structural features and property of lignin from bamboo. Ind. Crops Prod. 2013, 42, 332-343. [CrossRef]

30. Hashmi, S.F.; Meriö-Talvio, H.; Hakonen, K.J.; Ruuttunen, K.; Sixta, H. Hydrothermolysis of organosolv lignin for the production of bio-oil rich in monoaromatic phenolic compounds. Fuel Process. Technol. 2017, 168, 74-83. [CrossRef]

31. Segal, L.; Creely, J.; Martin, A., Jr.; Conrad, C. An empirical method for estimating the degree of crystallinity of native cellulose using the X-ray diffractometer. Text. Res. J. 1959, 29, 786-794. [CrossRef]

32. Granata, A.; Argyropoulos, D.S. 2-Chloro-4, 4, 5, 5-tetramethyl-1, 3, 2-dioxaphospholane, a reagent for the accurate determination of the uncondensed and condensed phenolic moieties in lignins. J. Agric. Food Chem. 1995, 43, 1538-1544. [CrossRef]

33. Jääskeläinen, A.; Sun, Y.; Argyropoulos, D.; Tamminen, T.; Hortling, B. The effect of isolation method on the chemical structure of residual lignin. Wood Sci. Technol. 2003, 37, 91-102. [CrossRef]

34. Xiao, L.P.; Wang, S.; Li, H.; Li, Z.; Shi, Z.J.; Xiao, L.; Sun, R.C.; Fang, Y.; Song, G. Catalytic hydrogenolysis of lignins into phenolic compounds over carbon nanotube supported molybdenum oxide. ACS Catal. 2017, 7, 7535-7542. [CrossRef]

35. Van den Bosch, S.; Koelewijn, S.F.; Renders, T.; Van den Bossche, G.; Vangeel, T.; Schutyser, W.; Sels, B.F. Catalytic Strategies Towards Lignin-Derived Chemicals. Top. Curr. Chem. 2018, 376, 36. [CrossRef]

36. Bouxin, F.P.; McVeigh, A.; Tran, F.; Westwood, N.J.; Jarvis, M.C.; Jackson, S.D. Catalytic depolymerisation of isolated lignins to fine chemicals using a Pt/alumina catalyst: part 1-impact of the lignin structure. Green Chem. 2015, 17, 1235-1242. [CrossRef]

37. Zijlstra, D.S.; Analbers, C.A.; Korte, J.D.; Wilbers, E.; Deuss, P.J. Efficient mild organosolv lignin extraction in a flow-through setup yielding lignin with high $\beta-\mathrm{O}-4$ content. Polymers 2019, 11, 1913. [CrossRef]

38. Song, Q.; Wang, F.; Cai, J.; Wang, Y.; Zhang, J.; Yu, W.; Xu, J. Lignin depolymerization (LDP) in alcohol over nickel-based catalysts via a fragmentation-hydrogenolysis process. Energy Environ. Sci. 2013, 6, 994-1007. [CrossRef]

39. Wen, J.L.; Sun, S.L.; Xue, B.L.; Sun, R.C. Recent advances in characterization of lignin polymer by solution-state nuclear magnetic resonance (nmr) methodology. Materials 2013, 6, 359-391. [CrossRef]

40. Yuan, T.Q.; Sun, S.N.; Xu, F.; Sun, R.C. Structural characterization of lignin from triploid of Populus tomentosa Carr. J. Agric. Food Chem. 2011, 59, 6605-6615. [CrossRef]

41. Chen, T.Y.; Wang, B.; Wu, Y.Y.; Wen, J.L.; Liu, C.F.; Yuan, T.Q.; Sun, R.C. Structural variations of lignin macromolecule from different growth years of Triploid of Populus tomentosa Carr. Int. J. Biol. Macromol. 2017, 101, 747-757. [CrossRef] [PubMed]

42. Schutyser, W.; Van den Bosch, S.; Renders, T.; De Boe, T.; Koelewijn, S.F.; Dewaele, A.; Sels, B.F. Influence of bio-based solvents on the catalytic reductive fractionation of birch wood. Green Chem. 2015, 17, 5035-5045. [CrossRef] 
43. Sun, Z.H.; Barta, K. Cleave and couple: toward fully sustainable catalytic conversion of lignocellulose to value added building blocks and fuels. Chem. Commun. 2018, 54, 7725-7745. [CrossRef] [PubMed]

44. Upton, B.M.; Kasko, A.M. Strategies for the conversion of lignin to high-value polymeric materials: Review and perspective. Chem. Rev. 2016, 116, 2275-2306. [CrossRef] [PubMed]

45. Ding, S.Y.; Liu, Y.S.; Zeng, Y.; Himmel, M.E.; Baker, J.O.; Bayer, E.A. How does plant cell wall nanoscale architecture correlate with enzymatic digestibility? Science 2012, 338, 1055-1060. [CrossRef] [PubMed]

46. Zeng, Y.; Zhao, S.; Yang, S.; Ding, S.Y. Lignin plays a negative role in the biochemical process for producing lignocellulosic biofuels. Curr. Opin. Biotechnol. 2014, 27, 38-45. [CrossRef]

47. Sun, S.L.; Wen, J.L.; Ma, M.G.; Sun, R.C. Enhanced enzymatic digestibility of bamboo by a combined system of multiple steam explosion and alkaline treatments. Appl. Energy 2014, 136, 519-526. [CrossRef]

(C) 2020 by the authors. Licensee MDPI, Basel, Switzerland. This article is an open access article distributed under the terms and conditions of the Creative Commons Attribution (CC BY) license (http://creativecommons.org/licenses/by/4.0/). 